\title{
Skin Nodular Solid Basal Cell Carcinoma
}

National Cancer Institute

\section{Source}

National Cancer Institute. Skin Nodular Solid Basal Cell Carcinoma. NCI Thesaurus. Code C5616.

A basal cell carcinoma often presenting as elevated skin nodules which may become ulcerated or cystic. In cases which present as endophytic nodules, the overlying skin surface shows indurated flat lesions. It occurs most frequently on the head. Morphologically, the neoplastic basaloid cells form lobules with peripheral nuclear palisading. 